\title{
EXPERIMENT AND PREDICTION
}

IN THE BENDING OF. A NICKEL

BEAM AT $200^{\circ} \mathrm{C}$

by

J.A. Mautz \& E.W. Hart
This report was prepared as an account of work sponsored by the United States Government. Neitment of United States nor the United Slates Depary of their Energy, nox any of their employees, nor any of makes contractors, subcontractors, or thei, erployes any legal any warranty, express or implied, or ascy, completeness liability of responsibuity for the accuatus, product or process disclosed, or represents that its use would not infringe privately owned rights.

\footnotetext{
Department of Theoretical and Applied Mechanics Corne11 University Ithaca, NY 14853
}

DOE . Report No, C00-2733-21

\section{Prepared by Cornell University} under Department of Energy

Contract No, EG-77-S-02-2733 


\section{DISCLAIMER}

This report was prepared as an account of work sponsored by an agency of the United States Government. Neither the United States Government nor any agency Thereof, nor any of their employees, makes any warranty, express or implied, or assumes any legal liability or responsibility for the accuracy, completeness, or usefulness of any information, apparatus, product, or process disclosed, or represents that its use would not infringe privately owned rights. Reference herein to any specific commercial product, process, or service by trade name, trademark, manufacturer, or otherwise does not necessarily constitute or imply its endorsement, recommendation, or favoring by the United States Government or any agency thereof. The views and opinions of authors expressed herein do not necessarily state or reflect those of the United States Government or any agency thereof. 


\section{DISCLAIMER}

Portions of this document may be illegible in electronic image products. Images are produced from the best available original document. 


\begin{abstract}
The results of an experiment on the bending response of a Nickel prismatic beam under four point loading at $200^{\circ} \mathrm{C}$ are described. The specimens have been subjected to histories of steady applied moment with a sequence of step changes both positive and negative. The measured results are compared with predictions based on Hart's constitutive equations.

The experimental conditions and procedures are described. The experiment and the predictions are compared with prior studies.
\end{abstract}




\section{INTRODUCTION}

The validation of advanced constitutive relations for the non-elastic behavior of structural materials must include some demonstration of successful prediction of the response of engineering structure elements to a variety of loading histories. Three elements of investigation enter into such a validation procedure (1) specification of the material parameters of the constitutive equations from. independent testing routines, development of computation methods for the structure to be tested, employing the constitutive equations, and (3) experimental testing of specimen structures for comparison with prediction.

This report' describes the results of such a procedure for the bending of prismatic beams of Nickel 270 at $200^{\circ} \mathrm{C}$.

The experimental apparatus for carrying out these tests was first described by Chang and Lance (1), and the derivation of the computation technique was reported by Chang, Lance, and Mukherjee (2). The characterization of the $\mathrm{Ni} 270$ was reported by $\mathrm{Li}$ (3) and by Huang and $\mathrm{Li}$ (4). We shall review this background material briefly below and shall then describe the subsequent experimental modifications and the results of the tests.

II. THE TESTING OF ENGINEERING STRUCTURES

The testing of engineering structures under a significant range of loading histories is generally more complicated than the measurement of the homogeneous deformation of the materials of which the structure is fabricated. If the structure is too complex in form, it is difficult to 
measure the operative stresses at all points of the structure and the deformations that result may show considerable scatter of data. Furthermore, the analytical calculations for prediction of behavior become expensive and their reliability can be questionable. A major problem in such testing is that of characterizing the initial state of the material. Because of fabrication operations, the properties of the material may vary considerably over the extent of the structure.

For these reasons it is customary, in testing predictive methods, to examine especially simple structural elements. The simplest non-trivial structure is the prismatic "beam or bar subjected to bending about an axis of symmetry. It is this structure that is the subject of this report.

Even with so simple a"structure there are definite limits on the precision of such a measurement: The condition of pure bending can only be approximated with a specimen of finite size. The calculated results, therefore, are precise only for an ideal experimental loading. The imprecision results not only from the lack of ideality of four point loading relative to pure bencing but also from the concentrated nature of the load point contacts.

Another source of imprecision comes from the calculation of the analytical predictions. Because of the neglect of edge effects in the beam there is some loss of exactness. It is generally expected that such errors are small for small deflections; but the errors cannot be closely estimated.

For these reasons we must be cautious about overinterpreting the degree of agreement between experiment and analysis. 


\section{THE ANALYTICAL PREDICTIONS}

The analytical calculations are based on restriction to small deflections (small curvature of bending). The calculation procedure, which was described earlier (2), Is substantially of the type that has been employed in several prior investigations of beam bending. The principal difference in the current calculation is the use of Hart's constitutive equations. These are flow relations that account for real time deformation rates in terms of unrecoverable plastic-creep strain and of recoverable anelastic strain. The equations represent the effect of strain hardening through a scalar state variable called the hardness. The detailed form of the constitutive relations are described in ref. 2 .

The calculations have been reduced to a computer code, written in Fortran, that quickly computes the curvature as a function of time in response to the given history of loading moment. The computer program has been recently improved to reduce the timeof calculation. A typical run involving about twelve load changes takes about $1.0 \mathrm{~min}$, of computing time on the Cornell IBM $370 / 168$ computer.

The source of the parameters for the constitutive equations is the experiments carried out on Nickel 270 by $C-Y$. Li and coworkers $(3,4)$. The values of the parameters for $200^{\circ} \mathrm{C}$ are shown here in Table 2. The hardness" parameter. $\sigma_{0}^{*}$ for the initial state of the material is not included there since it is necessarily characteristic of the particular material specimen that is under consideration. That value in fact varied from test specimen to test specimen. The reason for this is discussed below with the test results. 
There is one point in this regard that affects the results of the calculation, that should be mentioned here.. When an initial value of specimen hardness $\sigma_{0}^{*}$ is introduced into the calculation, it is implicitly assumed that that is the value of $\sigma_{0}^{*}$ for all parts of the structure. This need not be the case. If there is much variability of $\sigma_{0}^{*}$ among specimens cut from an original bar stock, there is also a fair liklihood that there is some variation of $\sigma_{0}^{*}$ through the gage section. No provision for this has been made in the calculation procedure, and, even if there was, there would be no good way of determining that distribution of $\sigma^{*}$ before the calculation. Substantially the same comment applies to the possibility of a preexisting distribution of anelastic strain inherited from the bar stock preparation procedures.

The problems of the type just mentioned are, of course, present in any fabricated structure regardless of the constitutive equations that might be employed. "They simply reflect" a degree of ignorance of the starting state of the material elements. In some cases, stress relief and annealing prior to use produces some standardization or homogenization of initial properties. However, as noted below, even the annealing treatment employed in this work was not sufficient to accomplish much homogenization.

\section{THE EXPERIMENTAL APPARATUS}

The principal physical details of the experimental loading frame was discussed in ref. 1. Since some dimensional changes were made subsequently, a schematic diagram of the loading of the specimen is shown in Fig. 1. A more detailed schematic appears as Fig. 1 of ref, 1. 
The three principal features of the experimental arrangement are: (1) the ambient environment control, (2) the deadweight loading frame, the loading fixture, and the specimen temperature control chamber, and the data acquisition system. We shall describe these here briefly with special attention to any changes from the initial arrangement.

\section{Environment Control}

The entire loading frame and the data acquisition apparatus is enclosed in an insulated chamber to avoid measurement errors that might derive from environmental temperature changes. This is especially important since many of the test runs continued over several days: The temperature control system for the chamber consists of a 6000 BTU Carrier window mount air conditioner, a 1500 Watt electric heater, a circulating fan, and a thermostat for control of the heater operation. "The normal operation involved continuous moderate cooling level operation of the air conditioner with controlled counter heating by the electric heater. This is both inexpensive in initial equipment and very effective in operation since control of the heater is simple and continuous. With this system the chamber temperature was easily maintained within maximum, short term fluctuations of $\pm 1^{\circ} \mathrm{C}$.

\section{The Loading Frame and Thermal Oven}

The uniaxial creep load testing machine is a rigid frame containing an upper load train, depended from a load measuring cell, and a.lower load train, loaded from a mandrel on a freely rotating drum that supported weights on bands encircling the drum. The upper load train supports the 
two lower loading points in Fig. 1. The lower load train applies the downward load on the top loading points of the same figure. The loading frame is shown schematically in Fig. 2 along with the block diagram of the data acquisition system.

The principal changes in this system since the last report are the installation of an Instron Environmental Chamber, Mode1 A74-37, for specimen temperature control and some modifications in the four point loading fixture. The environmental chamber is mounted as shown in dashed lines in Fig. 2. The chamber is controlled by a Model 3110 Instron Controller. Temperature stability during tests was generally beter than $\pm 0.6^{\circ} \mathrm{C}$ at $200^{\circ} \mathrm{C}$. The loading fixture was redesigned and rebuilt to facilitate operation at elevated temperature. The fixture as originally built tends to "freeze" at elevated temperature because of relative expansion of component parts. The rollers did not rotate freely: There was also some indication that the application of load to the specimen by the rollers was too concentrated and could results in 1 ocal deformation at the load application points. The fixture dimensions were therefore enlarged, and the load application rollers were increased in diameter and mounted with needle bearing axles. These changes together with liberal Molycote lubiccation resulted in satisfactory operation at $200^{\circ} \mathrm{C}$.

\section{The Data Acquisition System}

The data acquisition system, shown schematically in Fig. 2, consists principally of an Acurex Autodata Nine data 1ogger. This is a high resolution multipurpose and multichannel scanning data acquisition instrument. Its output is recorded on a thermal printer tape and also, through a digital output interface, on a Cipher, 
Series H, Magnetic Tape Recorder. The inputs for the Autodata Nine are from three thermocouples (one for room temperature and two for the specimen), the load cell, and three LVDT's (linear variable differential transformer). The load cell strain bridge is excited with a Hewlett-Packart, Model 6111A power supply and the LVDT's are supplied. from, a Hewlett-Packard, Mode1 6112A power supply. These high precision power supplies were added recently when it became apparent that this was necessary for reliable instrumentation. Critical system voltages are further monitored by a DANA 5900 Digital : Multimeter.

\section{THE EXPERIMENTAL PROCEDURE}

A series of seven experimental specimens was tested at $200^{\circ} \mathrm{C}$. The results for Specimens 1 and 5 were discarded. The run on Specimen 1 was conducted in unannealed condition and was principally to test the experimental routine. The run on Specimen 5 is omitted because of mechanical failure of the loading fixture during the run, The remaining five specimen runs are described and analyzed below.

\section{Specimen Preparation}

High purity Nickel (Nickel 270) was purchased from A.D. Mackay, Darien, C.T. The chemical analysis, furnished by the manufacturer, is shown in Table 1. The Nickel was purchased as rolled bar with rectangular cross-section of $0.250 \mathrm{in.}$ by $2.000 \mathrm{in}$. and was $10 \mathrm{ft}$. in length. The bar was slit lengthwise, and two specimens of cross-section dimension 0.125 in. 
by $0.800 \mathrm{in}$, were prepared from each $10 \mathrm{in.}$ length of bar. The specimens were finished to dimension by milling and surfaced by grinding. All specimens except the first, as noted above, were degreased and then vacuum annealed for 2 hours at $650^{\circ} \mathrm{C}$.

As will be shown below, the annealing treatment was not sufficient to result in uniform hardness for all specimens and, therefore, it is probable that there was also a lack of homogeneity with respect to hardness within individual specimens.

\section{Experimental:Procedure}

For each experimental run, a specimen was mounted and alligned in the four point bending fixture. The room temperature was allowed to stabilize at a controlled temperature of $20^{\circ} \mathrm{C}$. The environmental chamber (oven) was then activated and brought to operating temperature. Stable operating temperature was observed for a minimum of two hours before beginning the loading sequence.

Proper operation of the data acquisition system was verified both before and after heating the oven;. This involved specially a verification of reliable contact of the sensing rods of the LVDT's with the gage portion of the specimen. Loading of the initial minimum load on the load train was accomplished by operating a scissors jack that supported the initial weight of the load train during set-up. The subsequent load changes were accomplished by loading and unloading the suspension bands on the drum. 
After each load change, readings were taken at intervals of about one minute. The interval between readings was progressively increased in steps to 30,45 , and 60 minutes. The parameters that were monitored at each scan were time, temperature. (three thermocouples), load cell, and three LVDT's. The readings were simultaneously recorded on paper print-out and on magnetic tape.

VI. EXXERIMENTAL RESULTS

After each rum the data from the magnetic tape was read by the IBM 370 computer to prepare an input file for a program that computed, from that data, the record of moment and curvature as a function of time. The record of loading history was then employed in the prediction program to compute the predicted curvature of bending history. The results from this program depend on the input parameter that reflect the initial value of $\sigma^{*}$ for the specimen under consideration. Some adjustment was also made in the program for the value of Young's Modulus E. This value was determined so that the predicted elastic curvature changes agreed with the measured ones. All other parameters were the same for all runs.

The plots of the results are shown for five specimens in Figs. $3-7$. In each figure the record of measured and best predicted curvature is plotted adjacent to the record of applied bending moment. The tabulation of values of the specimen parameters for each run is shown in Table 3.

For all specimens there are loading histories that involve both increasing and decreasing moment sequences. All runs show appreciable long 
time creep. The substantial variation in initial hardness among the specimens is evident from the plots and from the values of $\sigma_{0}^{*}$ shown in Table 3.

There is one feature of the results that warrants special mention. In the results for Specimens 2, 6, and 7, during the last loading sequences, the predicted deflection exceeds the measured one at the intermediate load level. Even though the initial flow in those segments is lower than predicted, the resultant steady creep agrees well with that predicted, and finally at higher loading the discrepancy disappears. It is difficult to explain this behavior in any simple way. It does not seem to be dependent on the measurement technique since the behavior is observed at different curvature and moment levels. We shall discuss this further in the next section.

VIT. DISCUSSTON

The agreement between measured and predicted behavior is clearly very good. This is especially notable since the temperature at which the test has been performed is one for which both high and low temperature effects are simultaneously present, This temperature, which is about one-third of the melting temperature, is in fact a practical temperature for some structural application. The constitutive model that was employed for the predictions describes both large plastic deformation and long term creep at this temperature. No other constitutive model has successfully accomplished this for this material. 
The only prior reported works on bending at intermediate homologous temperature are those by Marin and Zwissler (6) and by Sim and Penny (7). Both are on Alumninum, which, at room temperature, is at a homologous temperature comparable to that of Nickel at $200^{\circ} \mathrm{C}$. The work of Marin and Zwissler ignores the plastic or transient deflections and measures only single creep rates. The data is then fit by a power. creep law which is inappropriate to the material. The work of Sim and Penny is addressed to testing the "reference stress". techniques which has been proposed as :a computing technique. The tests were restricted to single load creep histories of small total strain. The constitutive theory employed was simply the direct application of the measured uniaxial strain-time creep curve to a selected reference fiber. These relationships cannot be adapted to more complex structures or loading histories.

The experiment reported here has attempted to verify agreement between measurement and prediction on a much finer scale than have any prior investigations. The success of this procedure has been due to the precision of the calculation procedure, and the degree of realism represented in the constitutive equations.

It remains to judge the significance of the agreement reported.

The principal discrepancy, although a small one, is that noted above with respect to Specimens $2 ; 6$ and 7 . The only explanation that is consistent with the known material properties and with the subsequent return to full agreement in these test runs is that the delay in accomplishing the full predicted plastic increments is due to strain aging of the Nickel. The effect of strain aging would be like the effect observed in this experiment. 
There was of course ample aging time under load prior to each anomalous region. During the anomalous run interval the specimen could respond at that load increment with the slow creep strain rate but could not provide the high rate flow required for the plastic increment. At subsequent higher moment, full break-away occurs and accomplishes the full plastic increment cumulatively.

There is considerable evidence for strain aging of Nickel in the literature $(8,9)$, and Chao $(10)$ observed a maximum in the dislocation friction parameter at about $200^{\circ} \mathrm{C}$ for the same material as was used here.

It is certainly possible that there was some inhomogeneity in the specimens as measured. In such case the value of $\sigma_{0}^{*}$ is not in fact the same for all elements of the specimen and the value assigned to describe the specimen is some average over the actual values. It is not possible to estimate the degree of error that might result from such a circumstance. However, the consistency of the results implies that good predictive accuracy can be expected nevertheless for somewhat non-uniform structures so long as the assigned starting values for the principal state variable $\sigma^{*}$ corresponds to the most sensitive part of the structure.

\section{VITI CONCLUSTONS}

It can be safely concluded that the behavior of a simple structure can be predicted in considerable detail from the measured properties of the metal from which it is fabricated when its deformation behavior is described by Harts constitutive equations. Of particular importance is that the major 
plastic flow and the long term creep are both described well as a real time flow.

The analytical methods for applying Hart's constitutive equations are both effective and economical. 


\section{Acknowledgments}

The research reported here was supported under Contract No. EY-76-S-02-2733 of the United States Department of Energy. 


\section{References}

1. K.J. Chang and R.H. Lance, "Design of a uniaxial load creep testing machine", Cornel1 Report No. C00-2733-10, May 1977.

2. K.J. Chang, R.H. Lance, and S. Mukherjee, "Inelastic bending of beams under time-varying moments - A state variable approach", Cornell Report No. C00-2733-15, January 1978.

3. C-Y. Li, "Deformation in Type 304 Stainless Stee1", Project Report RP-697-1, prepared for EPRI, Corne11 University, June 1977.

4. F.H. Huang and $\mathrm{C}-\mathrm{Y} \mathrm{Li}$, "A work hardening correlation for monotonic loading based on state variables", Corne11 Report No. C00-2172-19,

5. E.W. Hart, "Constitutive relations for the non-elastic deformation of meta1s", J. Eng. Matls, and Tech., Trans., ASME, Series H, Vol. 98, pp. 193-202, July 1976.

6. J. Marin and L.E. Zwissler; "Creep of Aluminum Subjected to bending at normal temperatures", Proc. ASTM, 40, 937 (1940).

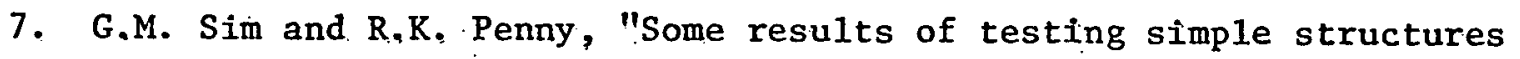
under constant and variable loading during creep", Experimental Mechanics; 10,152 (1970).

8. W.D. Jenkins and T.G. Digges, "Effect of Temperature on the Tensile Properties of High Purity Nickel", N.B.S. Journal of Research, 48,313 (1952). 
9. P.R. Landon, J.L. Lytton, L,A, Shepard, and J.E. Dorn, "The Activation Energies for Creep of Polycrystalline Copper and Nickel", Trans. ASM, 900 (1959).

10. S-J. Chao, "Plastic equation of state in Nicke1", Masters Thesis, Cornell University, 1976. 
Table 1. Chemical specifications of $\mathrm{Ni} 270$ specimens.

$\begin{array}{lc}\text { Component } & \text { Percentage } \\ \mathrm{Ni} & 99.98 \\ \mathrm{C} & 0.01 \\ \mathrm{Fe} & 0.003 \\ \mathrm{Mn} & <0.001 \\ \mathrm{~S} & <0.001 \\ \mathrm{Si} & <0.001 \\ \mathrm{Cu} & <0.001 \\ \mathrm{Cr} & <0.001 \\ \mathrm{Ti} & <0.001 \\ \mathrm{Co} & <0.001\end{array}$


Table 2. Values of material parameters used in Hart's constitutive equations for all specimens.

$$
\begin{array}{ll}
\lambda=0.15 & \beta=3.1 \times 10^{6} \mathrm{kN} / \mathrm{m}^{2} \\
M=7.5 & M=1.38 \times 10^{9} \mathrm{kN} / \mathrm{m}^{2} \\
\mathrm{~m}=5.0 & \dot{a}^{*}=2.9 \times 10^{34} \mathrm{~s}^{-1} \\
\delta=1.64 & \sigma_{\mathrm{s}}^{*}=1.38 \times 10^{5} \mathrm{kN} / \mathrm{m}^{2} \\
\gamma=0.30 &
\end{array}
$$


Table 3. Values of material parameters used in Hart's constitutive equations.

$\begin{array}{cccccc}\text { Specimen Number } & 2 & 3 & 4 & 6 & 7 \\ \sigma^{*}\left(10^{5} \mathrm{kN} / \mathrm{m}^{2}\right) & 1.15 & 1.04 & 0.883 & 0.969 & 0.969 \\ \mathrm{E}\left(10^{8} \mathrm{kN} / \mathrm{m}^{2}\right) & 2.14 & 2.23 & 2.23 & 2.14 & 2.14 \\ \dot{\varepsilon}_{\mathrm{s}}^{*}\left(10^{-21} \mathrm{~s}^{-1}\right) & 0.40 & 0.24 & 0.11 & 0.17 & 0.17\end{array}$




\section{FIGURE CAPTIONS}

Figure 1. Schematic diagram of four point loading apparatus for testing - of beam bending. The principal dimensions are shown for loading points and points of contact for LVDT points. (All dimensions in inches).

Figure 2, General schematic of uniaxial creep testing system set up for four point bending.

Figure 3. Measured and calculated curvature for four point bending of a Nickel beam as a function of time shown with bending moment history. For the experiment at $200^{\circ} \mathrm{C}$, the material parameters are: $\sigma^{*}=1.15 \times 10^{5} \mathrm{kN} / \mathrm{m}^{2}, \quad E=2.14 \times 10^{8} \mathrm{kN} / \mathrm{m}^{2}$, and $\dot{\varepsilon}_{\mathrm{S}}^{*}=0.40 \times 10^{-21} \mathrm{~s}^{-1}$.

Figure 4. Measured and calculated curvature for four point bending of a Nickel beam as a function of time shown with bending moment history. For the experiment at $200^{\circ} \mathrm{C}$, the material parameters are: $\sigma^{*}=1.04 \times 10^{5} \mathrm{kN} / \mathrm{m}^{2}, E=2.33 \times 10^{8} \mathrm{kN} / \mathrm{m}^{2}$, and $\dot{\varepsilon}_{\mathrm{s}}^{*}=0.24 \times 10^{-21} \mathrm{~s}^{-1}$.

Figure 5. Measured and calculated curvature for four point bending of a Nickel beam as a function of time shown with bending moment history. For the experiment at $200^{\circ} \mathrm{C}$ the material parameters are: $\sigma^{*}=0.883 \times 10^{5} \mathrm{kN} / \mathrm{m}^{2}, \quad E=2.23 \times 10^{8} \mathrm{kN} / \mathrm{m}^{2}$, and. $\dot{\varepsilon}_{s}^{*}=0.11 \times 10^{-21} s^{-1}$.

Figure 6. Measured and calculated curvature for four point bending of a Nickel beam as a function of time shown with bending moment history. For the experiment at $200^{\circ} \mathrm{C}$, the material parameters are: $\sigma^{*}=0.969 \times 10^{5} \mathrm{kN} / \mathrm{m}^{2}, E=2.14 \times 10^{8} \mathrm{kN} / \mathrm{m}^{2}$, and $\dot{\varepsilon}_{\mathrm{s}}^{*}=0.17 \times 10^{-21} 1_{\mathrm{s}}-1$.

Figure 7. Measured and calculated curvature for four point bending of a Nickel beam as a function of time-shown with bending moment history. For the experiment at $200^{\circ} \mathrm{C}$, the material parameters are: $\sigma^{*}=0.969 \times 10^{5} \mathrm{kN} / \mathrm{m}^{2}, \quad E=2.14 \times 10^{8} \mathrm{kN} / \mathrm{m}^{2}$, and $\dot{\varepsilon}_{\mathrm{s}}^{*}=0.17 \times 10^{-21} \mathrm{~s}_{\mathrm{s}}^{-1}$. 


\section{BENDING MOMENT $=P L / 2$}

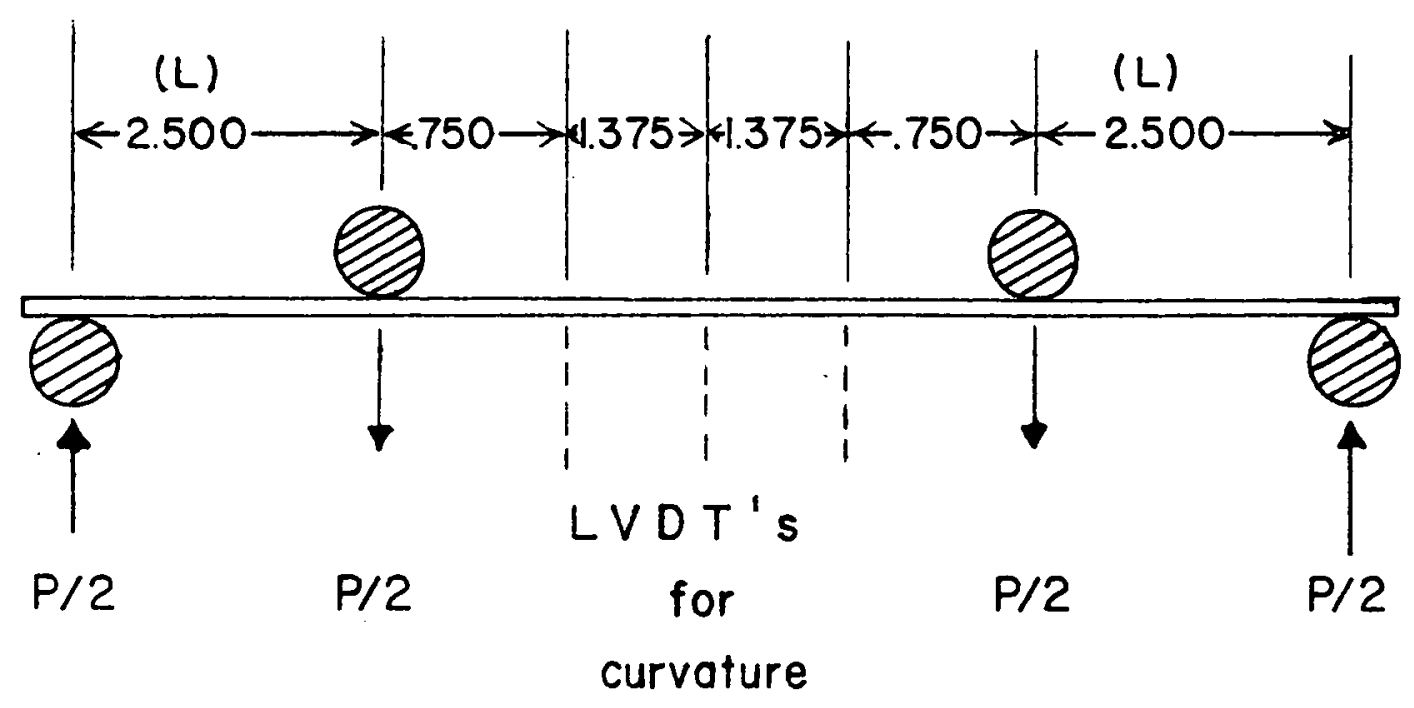

calculation

\section{FOUR POINT BEAM BENDING}

Figure 1. Schematic diagram of four point loading apparatus for testing of beam bending. The principal dimensions are shown for loading points and points of contact for LVDT points. (A11 dimensions in inches). 


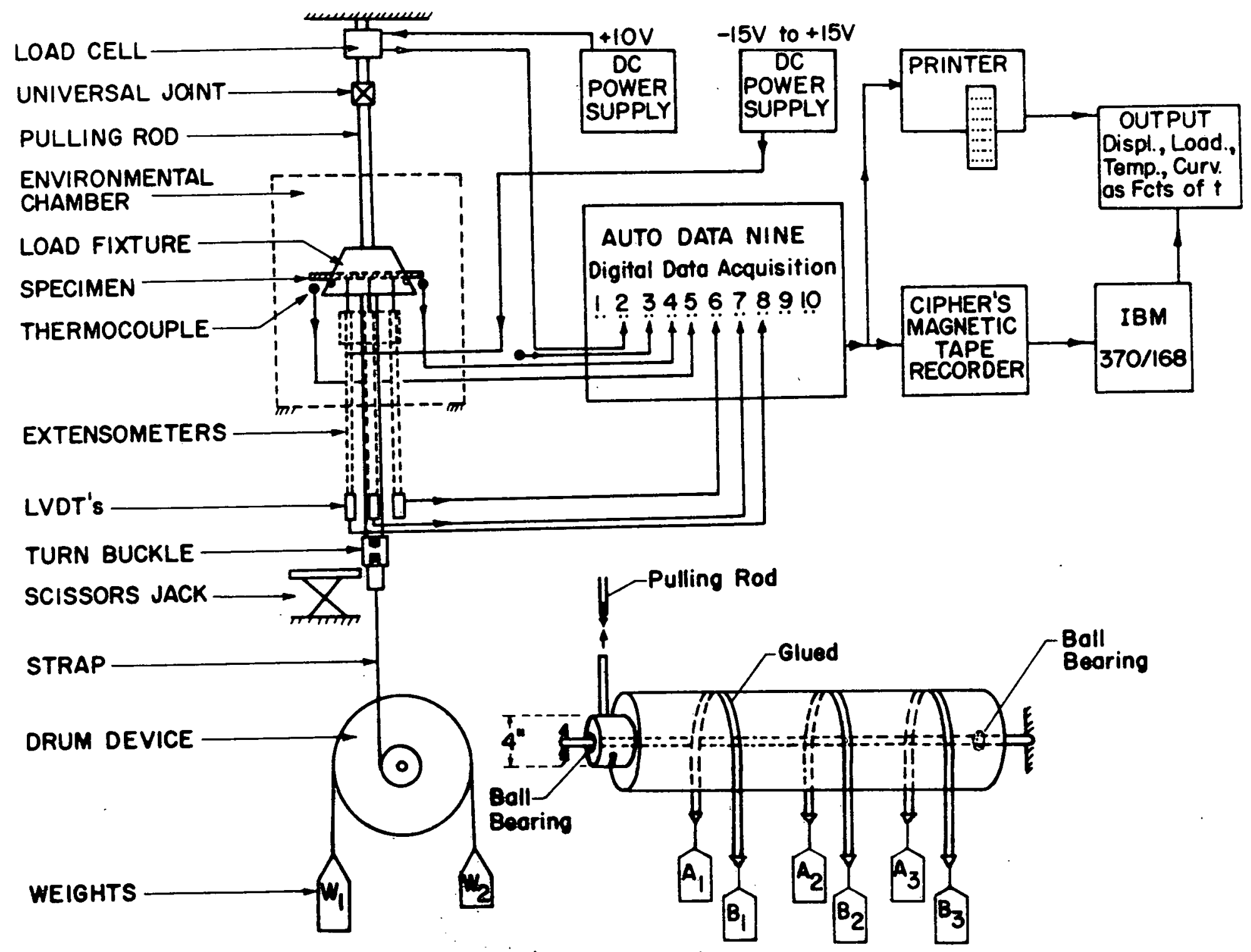

Figure 2. General schematic of uniaxial creep testing system set up for four point bending. 

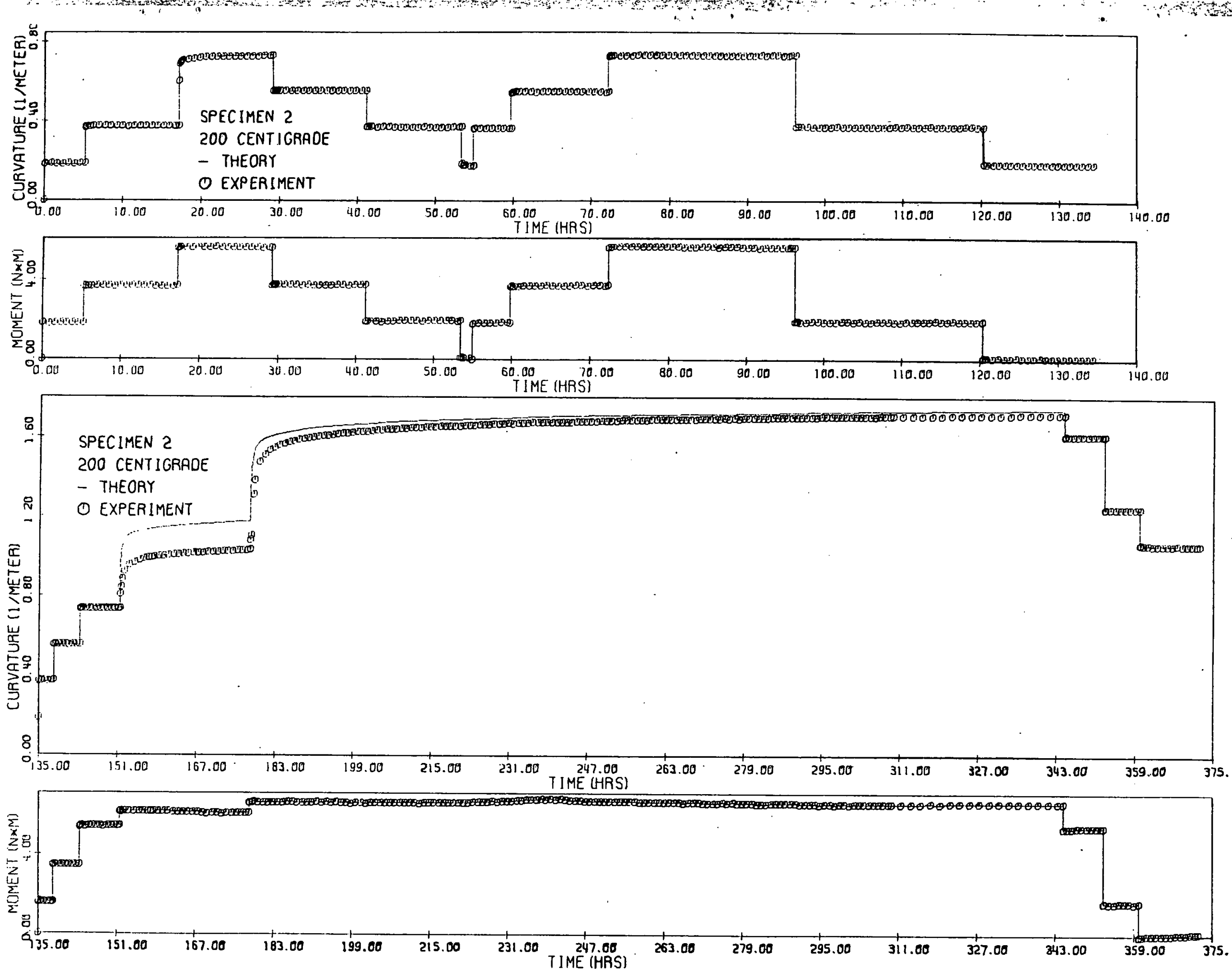

Figure 3. Curvature and bending moment history for four point bending of a Nickel beam. 

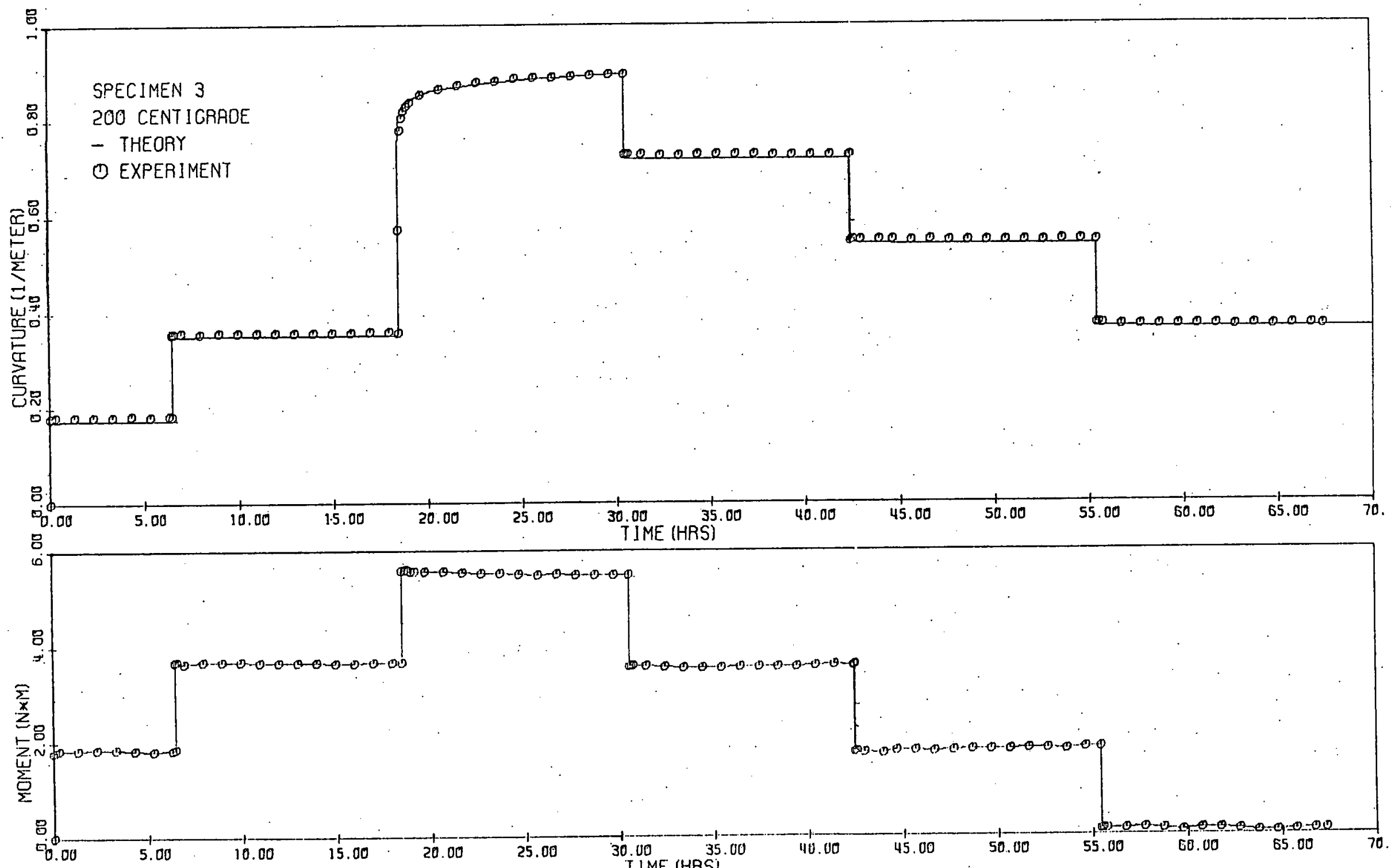

Figure 4. Curvature and bending moment history for four point bending of a Nickel beam. 


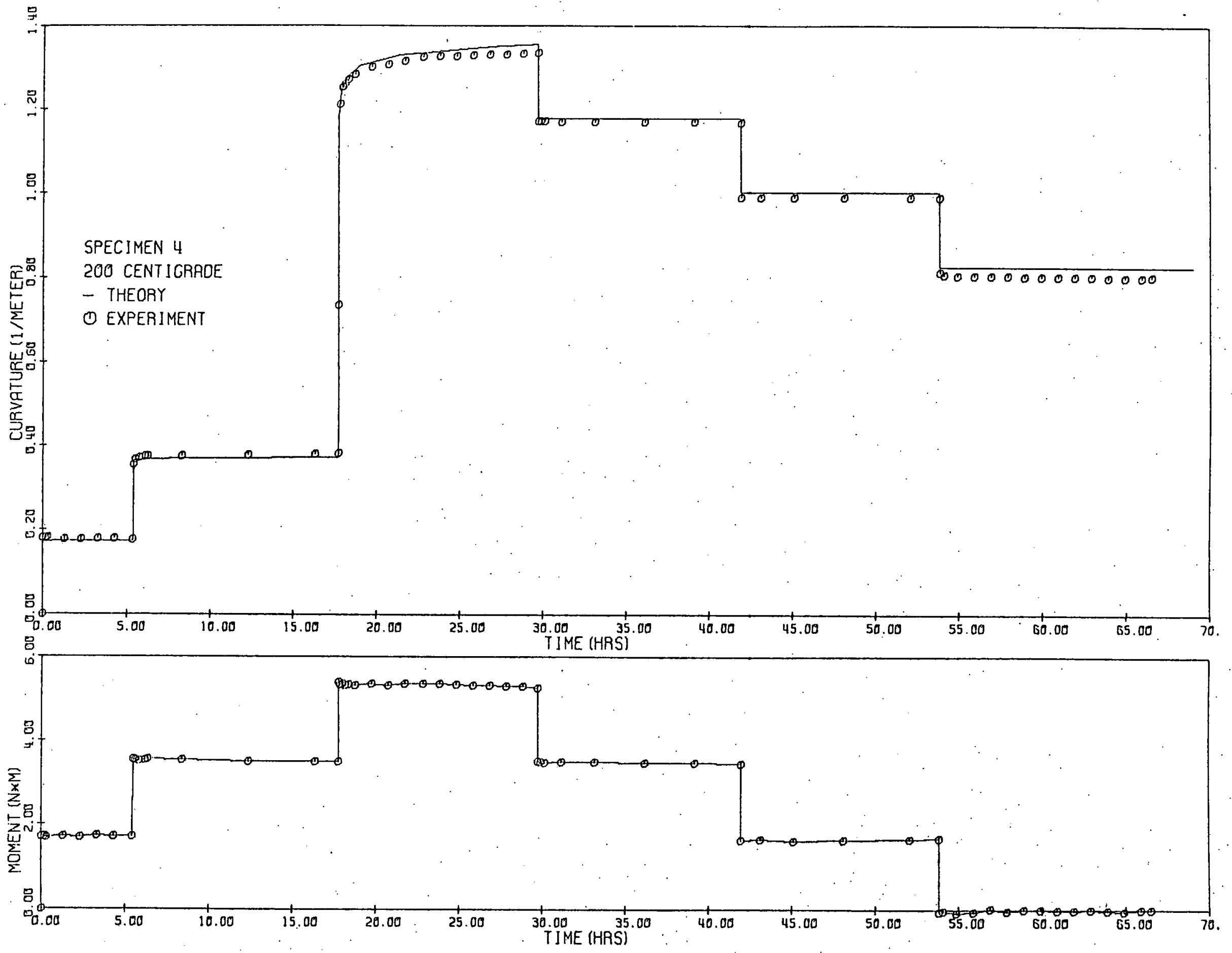

Figure 5. Curvature and bending moment history for four point bending of a Nickel beam. 

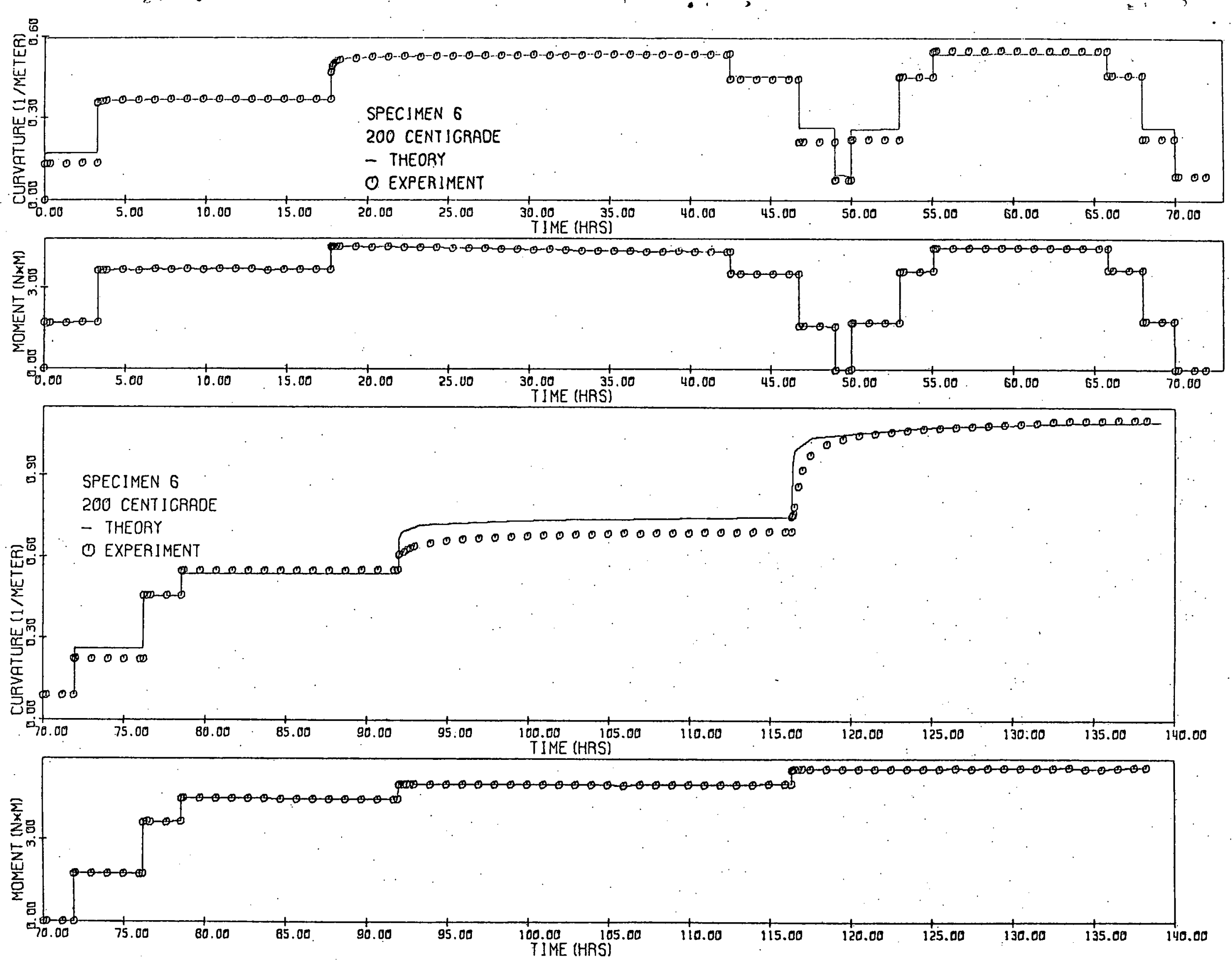

Figure 6. Curvature and bending moment history for four point bending of a Nickel beam. 


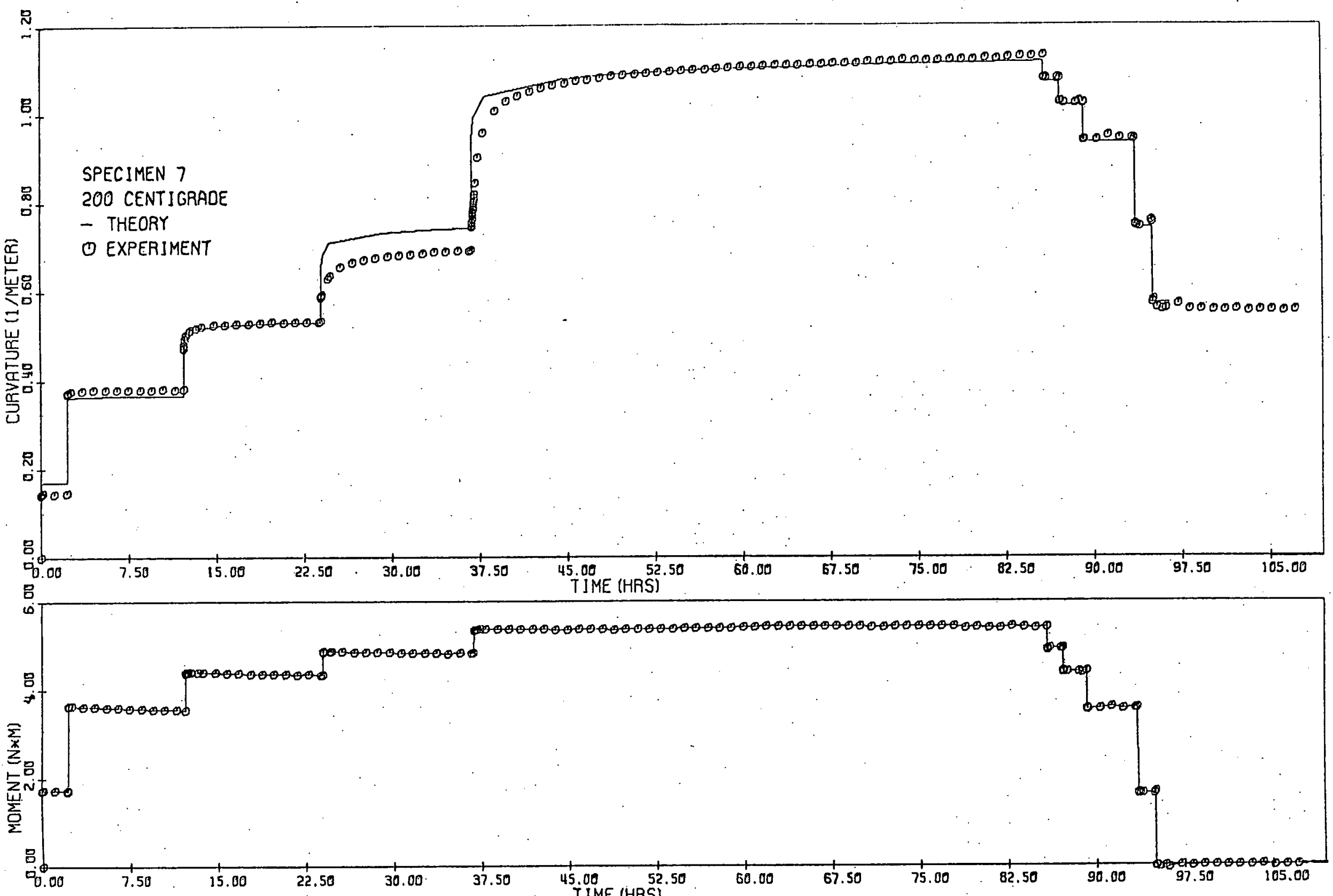

Figure 7. Curvature and bending moment history for four point bending of a Nickel beam. 